Q

Cipdates

Cite as

Nano-Micro Lett.

(2020) 12:177

Received: 15 May 2020

Accepted: 4 August 2020

Published online: 29 August 2020

(C) The Author(s) 2020

\title{
An Efficient Trap Passivator for Perovskite Solar Cells: Poly(propylene glycol) bis(2-aminopropyl ether)
}

Ningli Chen ${ }^{1,2}$, Xiaohui $\mathrm{Yi}^{1,3}$, Jing Zhuang ${ }^{1,2}$, Yuanzhi Wei ${ }^{1,2}$, Yanyan Zhang ${ }^{4}$, Fuyi Wang ${ }^{2,4}$, Shaokui $\mathrm{Cao}^{5}$, Cheng $\mathrm{Li}^{3}$, Jizheng Wang ${ }^{1,2} \bowtie$

$\triangle$ Jizheng Wang, jizheng@iccas.ac.cn

1 CAS Key Laboratory of Organic Solids, Beijing National Laboratory for Molecular Sciences, Institute of Chemistry Chinese Academy of Sciences, Beijing 100190, People's Republic of China

2 University of Chinese Academy of Sciences, Beijing 100190, People's Republic of China

Department of Physics, Xiamen University, Xiamen 361005, People's Republic of China

4 CAS Key Laboratory of Analytical Chemistry for Living Biosystems, Beijing National Laboratory for Molecular Sciences, Institute of Chemistry Chinese Academy of Sciences, Beijing 100190, People's Republic of China

5 School of Materials Science and Engineering, Zhengzhou University, Zhengzhou 450000, People's Republic of China

\section{HIGHLIGHTS}

- Poly(propylene glycol) bis(2-aminopropyl ether) (PEA) additive is introduced into the perovskite solar cells to passivate both surface and grain boundary defects, and hence improve the device efficiency and stability.

- $\mathrm{MAPbI}_{3}$ device with PEA exhibits significantly enhanced efficiency of $18.87 \%$. $\left(\mathrm{FAPbI}_{3}\right)_{1-\mathrm{x}}\left(\mathrm{MAPbBr}_{3}\right)_{\mathrm{x}}$ device with PEA exhibits enhanced efficiency of $21.60 \%$.

- The unsealed passivated device degrades only by $5 \%$ in PCE after being exposed to air ( $30 \pm 5 \%$ relative humidity) for 30 days.

\begin{abstract}
Perovskite solar cells (PSCs) are regarded as promising candidates for future renewable energy production. High-density defects in the perovskite films, however, lead to unsatisfactory device performances. Here, poly(propylene glycol) bis(2-aminopropyl ether) (PEA) additive is utilized to passivate the trap states in perovskite. The PEA molecules chemically interact with lead ions in perovskite, considerably passivate surface and bulk defects, which is in favor of charge transfer and extraction. Furthermore, the PEA additive can efficiently block moisture and oxygen to prolong the device lifetime. As a result, PEA-treated $\mathrm{MAPbI}_{3}\left(\mathrm{MA}: \mathrm{CH}_{3} \mathrm{NH}_{3}\right.$ ) solar cells show increased power conversion efficiency (PCE) (from 17.18 to $18.87 \%$ ) and good longterm stability. When PEA is introduced to $\left(\mathrm{FAPbI}_{3}\right)_{1-\mathrm{x}}\left(\mathrm{MAPbBr}_{3}\right)_{\mathrm{x}}(\mathrm{FA}$ : $\left.\mathrm{HC}\left(\mathrm{NH}_{2}\right)_{2}\right)$ solar cells, the PCE is enhanced from 19.66 to $21.60 \%$. For
\end{abstract}

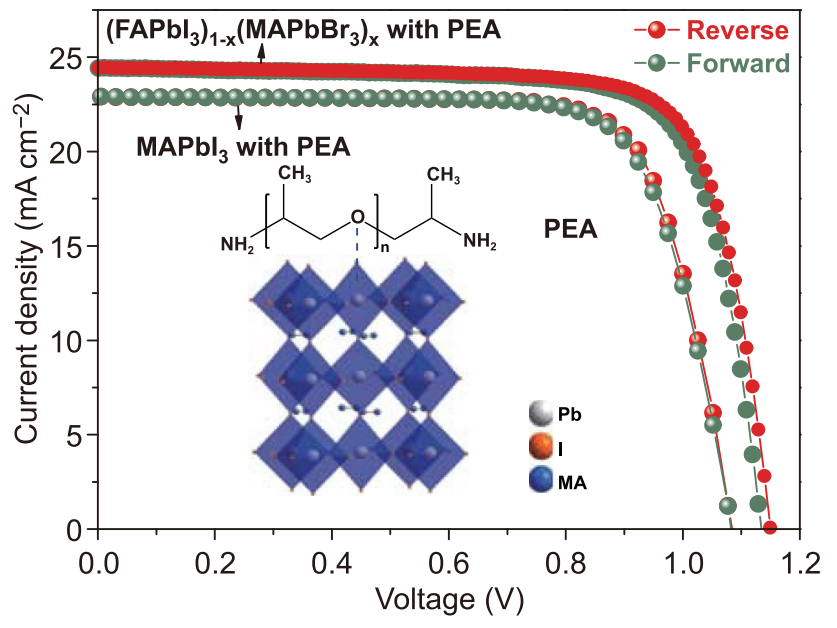
both perovskites, their severe device hysteresis is efficiently relieved by PEA.

KEYWORDS Defects; Grain boundaries; Passivation; Stability; Perovskite solar cells 


\section{Introduction}

Perovskite solar cells (PSCs) are attractive as next-generation photovoltaic devices due to their outstanding properties such as easy preparation, low cost, and high efficiency [1-5]. PSCs are first reported in 2009 [6], and since then, rapid progress has been made in improving their performances. Recently, a certified power conversion efficiency (PCE) of exceeding 25\% has been reported [7], reaching those of crystalline silicon solar cells [8]. However, a general and lasting problem for PSCs is that the perovskite films has abundant defects, at either surface or grain boundaries (GBs) [9]. These defects not only serve as recombination centers (to reduce carrier lifetime and charge extraction efficiency) $[10,11]$, but also facilitate the permeation of moisture and oxygen into the perovskite film, which seriously accelerates the device degradation [12-14]. Thus, defect passivation is highly desirable for achieving PSCs with both high PCE and high stability.

Surface passivation by coating molecules containing passivation groups on the surface of the perovskite layer has been proven successful for the enhancement of the device efficiency and durability. For example, the benzylamine-modified $\mathrm{FAPbI}_{3}\left(\mathrm{FA}: \mathrm{HC}\left(\mathrm{NH}_{2}\right)_{2}\right)$ solar cells exhibit a champion efficiency of $19.2 \%$ and prolonged moisture durability over 2900 h [15]. By adopting a poly(methyl methacrylate) polymer layer on the $\mathrm{MAPbI}_{3}$ film, the device stability in moisture air is largely enhanced [16].

GB passivation via introducing additives, such as metal ions [17], small organic molecules [18, 19], polymers [20, 21], and polymer-small molecules mixtures [22], in the perovskite layer, has been a route on improving the device performance. Among these additives, polymers preferentially incorporate between GBs due to their large sizes, are able to form stable and reliable interactions with perovskite grains [23], and hence have attracted significant research interest. Zuo et al. employed poly(4vinylpyridine) in $\mathrm{MAPbI}_{3}$, improved PCEs from 16.9 \pm 0.7 to $18.8 \pm 0.8 \%$ and gained prolonged shelf lifetime of up to 90 days [23]. Qin et al. reported that introducing polymer PBDB-T into $\left(\mathrm{CsPbI}_{3}\right)_{0.04}\left(\mathrm{FAPbI}_{3}\right)_{0.82}\left(\mathrm{MAPbBr}_{3}\right)_{0.14}$ leads to passivation of GBs. Consequently, the device shows an improved PCE of $19.85 \%$, and is able to retain about $90 \%$ of the initial PCE after 150 days [24].
In this study, we use poly(propylene glycol) bis(2-aminopropyl ether) (PEA), which contains rich ether-oxygen groups, for the perovskite surface and GB defect passivation. The PEA molecules existing at perovskite GBs and surface chemically interact with $\mathrm{Pb}$ ions, retarding trap-related nonradiative recombination and enhancing charge transfer and extraction. As a result, an improvement of PCE from 17.18 to $18.87 \%$ for $\mathrm{MAPbI}_{3}$ solar cells is observed. Moreover, the hydrophobic PEA molecules at GBs and surface can efficiently block moisture, which significantly strengthens the device stability in air. Without any encapsulation, the $\mathrm{MAPbI}_{3}$ device with PEA maintains $95 \%$ of its original PCE after 30 days. The PEAincorporated $\left(\mathrm{FAPbI}_{3}\right)_{1-\mathrm{x}}\left(\mathrm{MAPbBr}_{3}\right)_{\mathrm{x}}$ solar cells achieve an improved PCE from 19.66 to $21.60 \%$. For both perovskites, PEA efficiently eliminates their original serious device hysteresis.

\section{Results and Discussion}

\subsection{Characterization of $\mathrm{MAPbI}_{3}$ Films and Devices with PEA}

The chemical structure of a PEA molecule is shown in Fig. 1a. $\mathrm{Pb}^{2+}$ ions in perovskite have $6 \mathrm{p}$ empty electron orbits. The lone electron pairs from ether-oxygen in PEA can be delocalized to the empty orbits of $\mathrm{Pb}^{2+}$, forming coordination bonds $[23,25,26]$. The ether-oxygen unshared electron pair activates to form a crosslinking complex with lead ions at perovskite surface and GBs. As a result, the defect density is effectively decreased and the non-radiative recombination of the perovskite film is much inhibited [27]. This interaction is validated by Fourier transform Infrared (FTIR) spectra and X-ray photoelectron spectroscopy (XPS) measurements. Figure $\mathrm{S} 1$ displays the FITR spectra of PEA and the $\mathrm{MAPbI}_{3}$ films without (the control film) and with $1 \mathrm{wt} \%$ PEA. The PEA features a peak at $1110 \mathrm{~cm}^{-1}$, corresponding to the $\mathrm{C}-\mathrm{O}-\mathrm{C}$ stretching mode. The $\mathrm{C}-\mathrm{O}-\mathrm{C}$ peak shifts to a lower wavelength of $1064 \mathrm{~cm}^{-1}$ for the $\mathrm{MAPbI}_{3}$ film with PEA, and this is caused by the PEA molecule-perovskite interaction $[28,29]$. This interaction is further verified by performing XPS measurements on the $\mathrm{MAPbI}_{3}$ films with and without PEA. The overview spectra are shown 

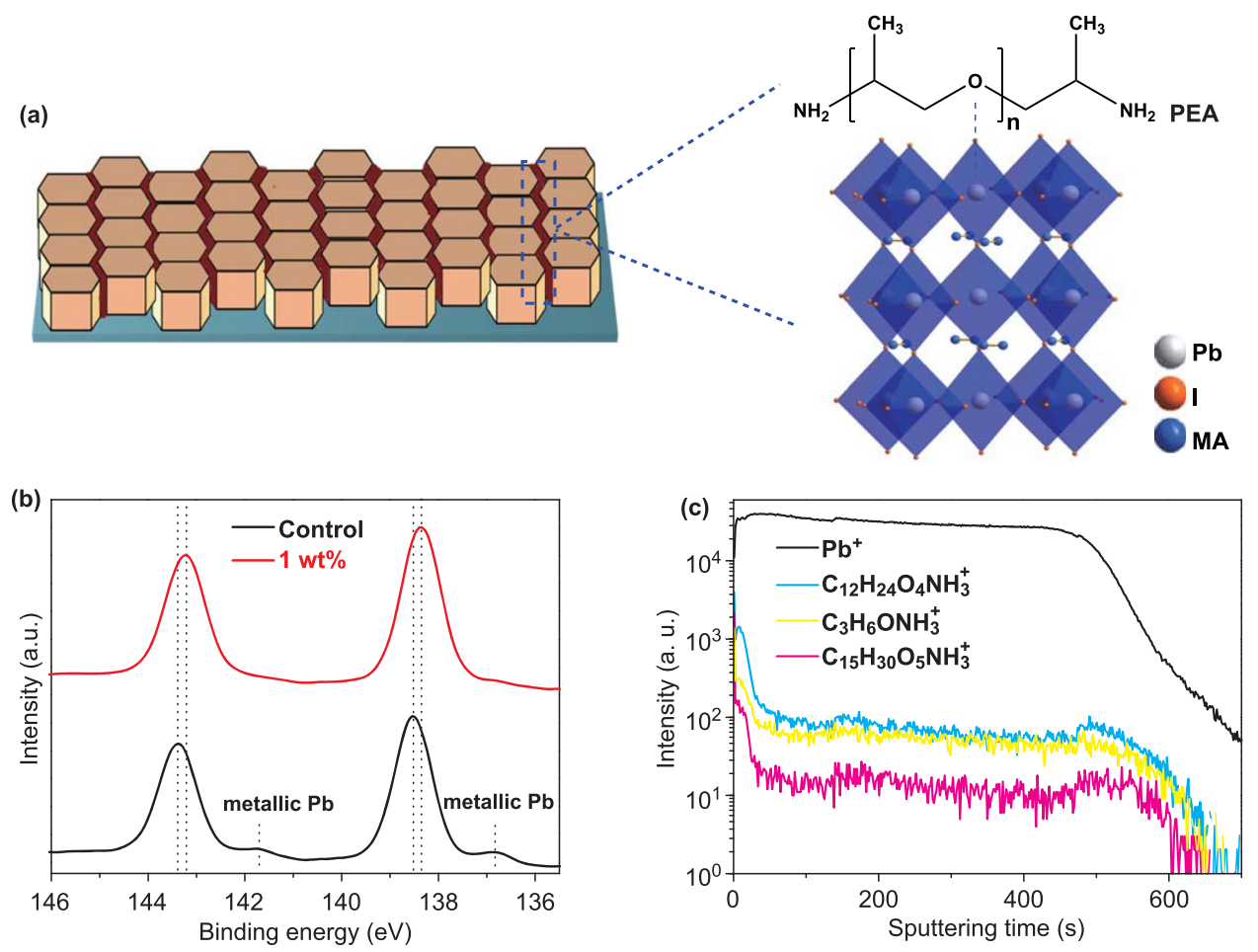

Fig. 1 a Schematic diagram of the GB passivation. b XPS spectra of $\mathrm{Pb} 4 \mathrm{f}$ for the $\mathrm{MAPbI}_{3}$ films with and without PEA, and $\mathbf{c}$ SIMS profiles showing $\mathrm{Pb}$ and $\mathrm{PEA}$ elements from the top to the bottom of the $\mathrm{MAPbI}_{3}$ film with $\mathrm{PEA}$

in Fig. S2 (the binding energy scale calibration has been done by measuring the $\mathrm{Au} 4 \mathrm{f}$ peak at $84.0 \mathrm{eV}$ ). The $\mathrm{C}$ 1s, N 1s, I 3d, O 1s spectra are shown in Fig. S3. The C 1s spectrum of the $\mathrm{MAPbI}_{3}$ film is fitted with several peaks of 285.0, 285.7, and $286.5 \mathrm{eV}$, which can be attributed to $\mathrm{CH}_{3} \mathrm{I}$, surface adsorbed oxygen, and $\mathrm{C}-\mathrm{N}$ bonds $[19,30]$. For the $\mathrm{C} 1 \mathrm{~s}$ spectrum of the $\mathrm{MAPbI}_{3}$ film with PEA, a new peak at about $287 \mathrm{eV}$ appears, which can be attributed to $\mathrm{C}-\mathrm{O}$ bonds in PEA [31]. And, the relative content of $\mathrm{C}-\mathrm{N}$ bonds increases when PEA is presented (PEA also contains $\mathrm{C}-\mathrm{N}$ bonds). The $\mathrm{Pb} 4 \mathrm{f}$ spectra are shown in Fig. $1 \mathrm{~b}$. The binding energy of $\mathrm{Pb} 4 \mathrm{f}_{7 / 2}\left(4 \mathrm{f}_{5 / 2}\right)$ shifts from 138.52 (143.39) to $138.35(143.21) \mathrm{eV}$. This shift confirms the decrease in cationic charge of $\mathrm{Pb}^{2+}$ ions in $\mathrm{MAPbI}_{3}$, which could be ascribed to the donation of a lone electron pair in PEA to the $6 p$ empty orbits of $\mathrm{Pb}^{2+}$ [32-35]. Moreover, there are two small peaks at 136.86 and $141.75 \mathrm{eV}$ in the $\mathrm{Pb} 4 \mathrm{f}$ spectrum of the control $\mathrm{MAPbI}_{3}$ film, which could be associated with the existence of metallic $\mathrm{Pb}$ [36]. The metallic $\mathrm{Pb}$ defects act as nonradiative recombination centers [37], hindering carrier transfer and collection. After PEA is added, these two small peaks diminish, implying the passivation of these defects. To study the PEA distribution throughout the $\mathrm{MAPbI}_{3}$ film with PEA, time-of-flight secondary-ion mass spectrometry (TOF-SIMS) tests were conducted. The " $\mathrm{Pb}^{+}$" from $\mathrm{MAPbI}_{3}, "\left(\mathrm{C}_{3} \mathrm{H}_{6} \mathrm{O}\right)_{\mathrm{n}} \mathrm{NH}_{3}{ }^{+}$" from PEA are tracked (Fig. 1c). It is found that $\left(\mathrm{C}_{3} \mathrm{H}_{6} \mathrm{O}\right)_{\mathrm{n}} \mathrm{NH}_{3}{ }^{+}$appear at the surface of the $\mathrm{MAPbI}_{3}$ film and exhibit a uniform distribution in the bulk film. Furthermore, due to the large size of the polymer, there is no opportunity for the PEA molecules to incorporate into the perovskite lattice. They would mainly accumulate in the gaps between GBs [29, 38-40], where passivation occurs.

We performed top-view scanning electron microscopy (SEM) measurements on the $\mathrm{MAPbI}_{3}$ films with various PEA concentrations (Fig. 2a-d). The control $\mathrm{MAPbI}_{3}$ film presents a compact surface morphology, with grain sizes ranging from 100 to $300 \mathrm{~nm}$. After $0.1 \mathrm{wt} \%$ PEA is added, the grain size decreases slightly. The size decrease is due to the inability of PEA to freely migrate, which has long molecule chain to hinder the growth of the perovskite 

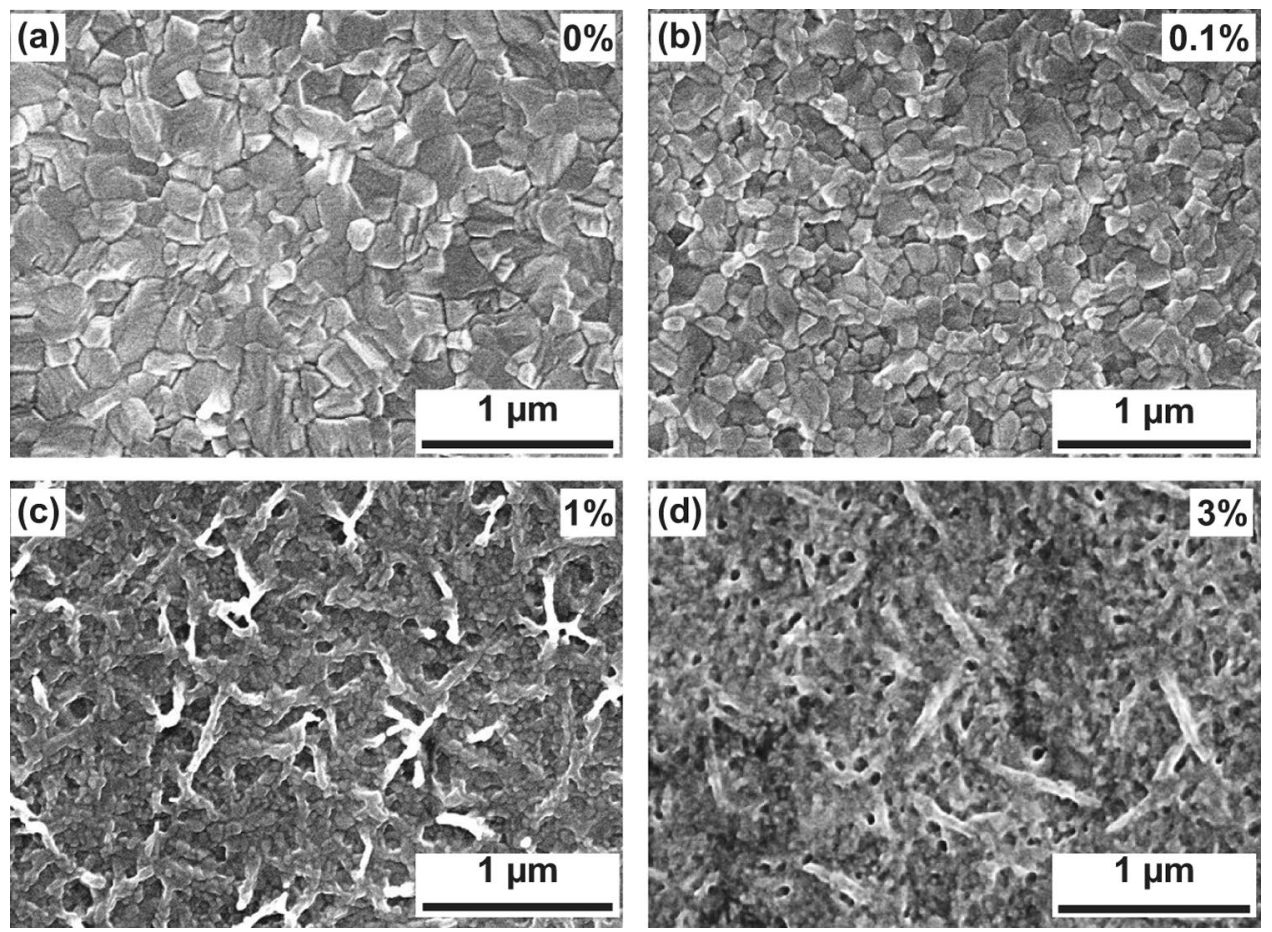

Fig. 2 Top view SEM images of the $\mathrm{MAPbI}_{3}$ films with different PEA concentrations with a $0 \mathrm{wt} \%$, b $0.1 \mathrm{wt} \%$, c 1 wt $\%$, and $\mathbf{d} 3$ wt $\%$

crystal [40]. As the PEA concentration is increased to 1 wt $\%$, branchlike features began to appear around GBs and on the surface, implying that the PEA molecules start to bridge the perovskite grains and occupy the perovskite surface. These branchlike features increase with increasing PEA concentration. When the PEA concentration is up to $3 \mathrm{wt} \%$, most of the surface is covered by the branchlike features. Owing to the weak conductive ability of PEA, it is expected that a thick PEA layer coating on the perovskite film would weaken the electron tunneling and hinders charge transfer. In addition, we performed cross-section SEM on the $\mathrm{MAPbI}_{3}$ films with (1 wt \%) and without PEA (Fig. S4). The control film exhibits a bumpy surface, while the $\mathrm{MAPbI}_{3}$ film with PEA displays a smooth surface.

X-ray diffraction (XRD) tests for the $\mathrm{MAPbI}_{3}$ films with and without PEA were conducted. Figure $3 \mathrm{a}$ indicates that the main diffraction peaks of the two films locate at the same positions of approximately $14.1^{\circ}, 28.4^{\circ}$, and $31.9^{\circ}$, which are consistent with the diffraction peaks of (110), (220), and (310) planes of the perovskite crystal, respectively [41]. Compared to the control film, the diffraction peak intensity of the $\mathrm{MAPbI}_{3}$ film with PEA increases slightly, indicating an enhanced crystallinity. From the
XRD spectra, we can conclude that the PEA additive is beneficial for the perovskite crystallization without affecting the perovskite crystal chemical structure. The absorption spectra of the $\mathrm{MAPbI}_{3}$ films with and without PEA are provided in Fig. 3b. The two films present same absorption edges, demonstrating that the band gap of the perovskite remains unchanged. The $\mathrm{MAPbI}_{3}$ film with PEA presents a slightly higher absorbance than the control film in the range from 400 to $750 \mathrm{~nm}$, indicating a better crystallinity [42]. The thermal and light stabilities of the two films are compared (Fig. 3c, d). The control $\mathrm{MAPbI}_{3}$ film is unable to endure both the thermal test $\left(80{ }^{\circ} \mathrm{C}\right.$ for $\left.70 \mathrm{~h}\right)$ and the light test (white light LED of 1 sun light intensity for $300 \mathrm{~h}$ ), while the film with PEA remains undamaged. After the tests, a new XRD peak at $12.7^{\circ}$, which corresponds to the (001) diffraction peak of $\mathrm{PbI}_{2}$ [43], appears for the control film, but not for the $\mathrm{MAPbI}_{3}$ film with PEA. The reasons for the retarded film degradation in the presence of PEA passivation could be explained as follows: Firstly, PEA could enhance perovskite crystallization. Secondly, PEA-perovskite interaction can suppress thermally induced and light-induced ions movement and desorption from the crystal $[39,44,45]$. 

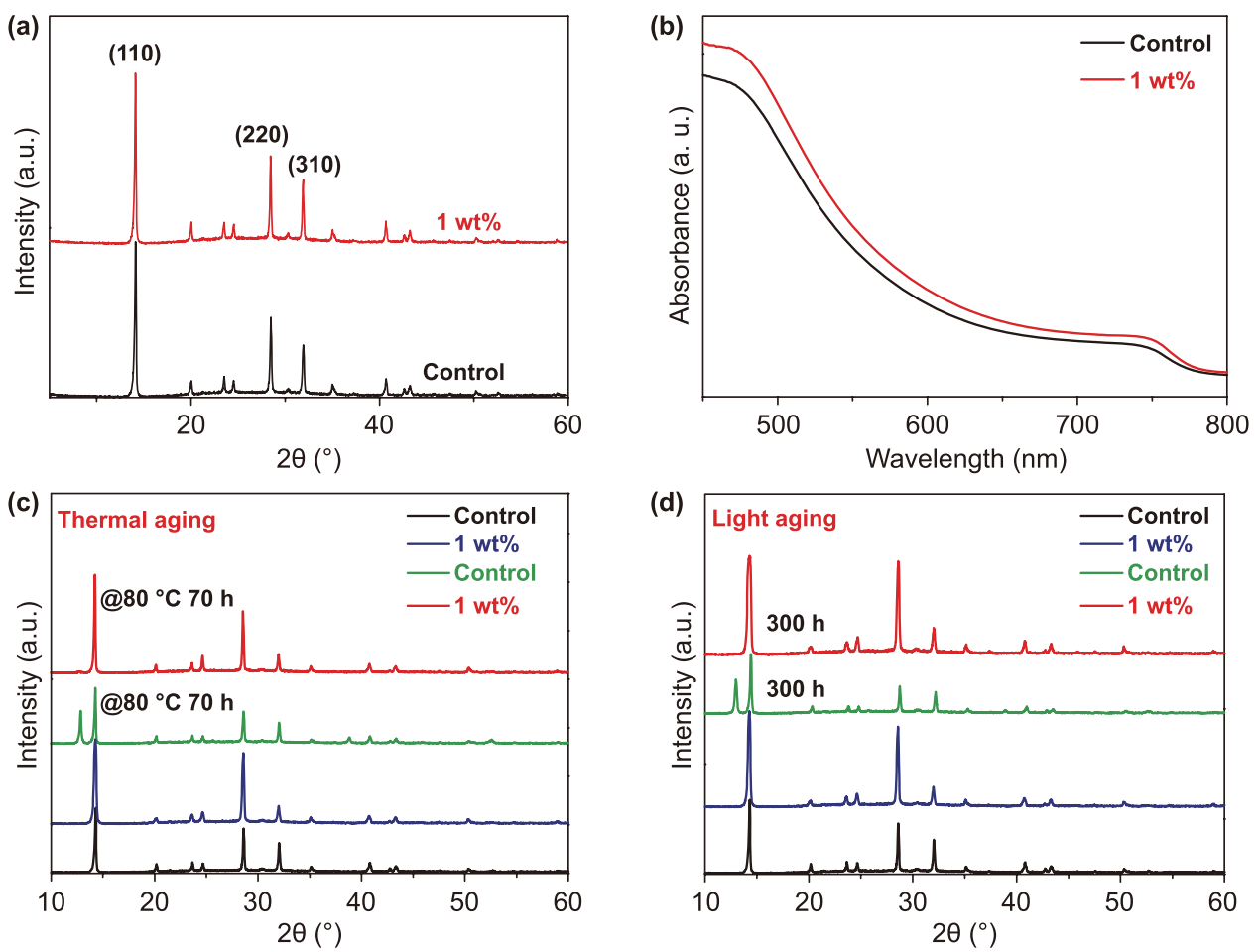

Fig. 3 a XRD spectra, b UV-Vis absorption spectra of the $\mathrm{MAPbI}_{3}$ films with and without PEA. c XRD spectra of the MAPbI ${ }_{3}$ films with and without PEA, before and after thermal aging at $80{ }^{\circ} \mathrm{C}$ for $70 \mathrm{~h}$, and $\mathbf{d}$ light aging for $300 \mathrm{~h}$
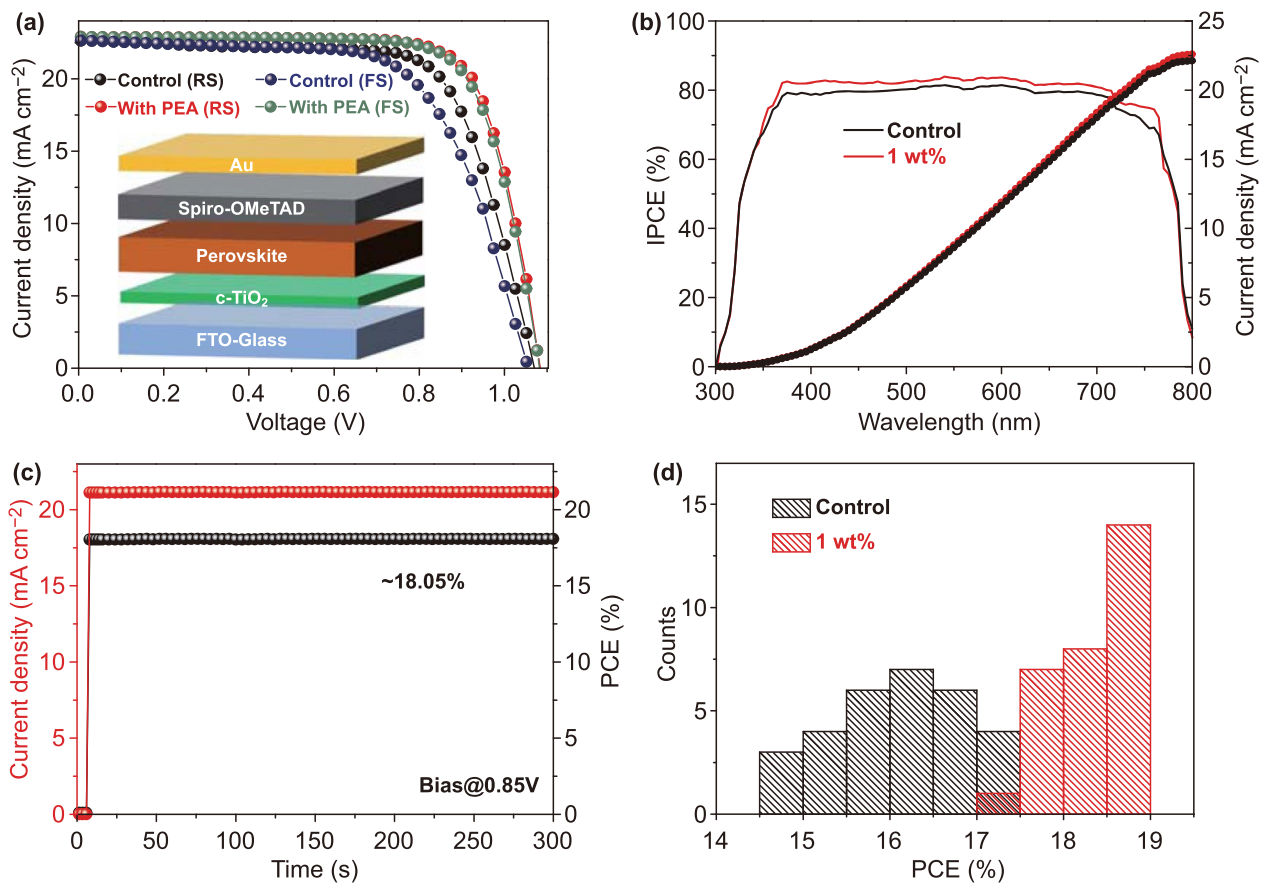

Fig. 4 a $J-V$ curves of the $\mathrm{MAPbI}_{3}$ devices with and without PEA (the inset gives the device structure). b IPCE spectra and integrated $\mathrm{J}_{\mathrm{SC}}$ of the two devices. c Steady-state current density and PCE at a constant bias of $0.85 \mathrm{~V}$ for the device with PEA. d Histogram of PCE distribution 
Planar heterojunction structure (PHJ) solar cells with a configuration of FTO-coated glass/ $/ \mathrm{TiO}_{2} / \mathrm{MAPbI}_{3} /$ SpiroOMeTAD/Au were fabricated. By optimization, the concentration of $1 \mathrm{wt} \%$ PEA leads to the optimal performance of PSCs (Fig. S5 and Table S1). Figure 4a shows the best PCE from the device with $1 \mathrm{wt} \%$ PEA. The detailed device parameters are provided in Table S2. Under reverse scan, the $\mathrm{MAPbI}_{3}$ device with PEA exhibits a PCE of $18.87 \%$, with $V_{\mathrm{OC}}$ of $1.08 \mathrm{~V}, J_{\mathrm{SC}}$ of $22.89 \mathrm{~mA} \mathrm{~cm} \mathrm{c}^{-2}$, and $\mathrm{FF}$ of $76.3 \%$. It outperforms the control device, which exhibits a PCE of $17.18 \%$, with $V_{\mathrm{OC}}$ of $1.08 \mathrm{~V}, J_{\mathrm{SC}}$ of $22.63 \mathrm{~mA} \mathrm{~cm}^{-2}$, and FF of $70.3 \%$. The improved PCE is mainly ascribed to the improvement of $J_{\mathrm{SC}}$ and $\mathrm{FF}$, which benefited from enhanced charge transport. In addition, hysteresis index (HI) values are calculated by Eq. (1) [20]:

$\mathrm{HI}=\frac{\mathrm{PCE}_{\text {reverse }}-\mathrm{PCE}_{\text {forward }}}{\mathrm{PCE}_{\text {reverse }}}$

The device with PEA has a HI value of 0.011 , which is significantly less than that of the control device (0.091). The negligible hysteresis can be attributed to efficient defect passivation by PEA. The incident photon to current conversion efficiency (IPCE) and integrated $J_{\mathrm{SC}}$ of the two devices are shown in Fig. 4b. Compared to the control device, the device with PEA has a higher spectral response in the range of $400-750 \mathrm{~nm}$. The calculated integrated $J_{\mathrm{SC}}$ from the IPCE spectrum of the device with PEA is $22.58 \mathrm{~mA} \mathrm{~cm}^{-2}$, and that of the control device is $22.11 \mathrm{~mA} \mathrm{~cm}^{-2}$. Both these results concurred with those from $J-V$ curves. We also recorded the photocurrent density and the PCE of the device with PEA and the control device as a function of time biased at its maximum power point voltage for $300 \mathrm{~s}$. As shown in Figs. S6 and Fig. 4c, the PCEs quickly stabilize at $18.05 \%$ and $16.22 \%$, respectively. To evaluate the reproducibility of the devices, two batches of 30 cells are fabricated. The histogram in Fig. 4d shows that the devices with PEA exhibit enhanced PCEs with narrower distributions.

Figure 5a presents the steady-state photoluminescence (PL) spectra of the $\mathrm{MAPbI}_{3}$ films with and without PEA on glass substrates. It is apparent that the PL peaks of the two films locate at the same energy position, and the $\mathrm{MAPbI}_{3}$ film with PEA shows stronger PL intensity. This demonstrates that nonradiative recombination in the perovskite film is suppressed. To explore the impact of PEA on charge carrier dynamics, time-resolved PL (TRPL) decay measurements of the two films were conducted, and
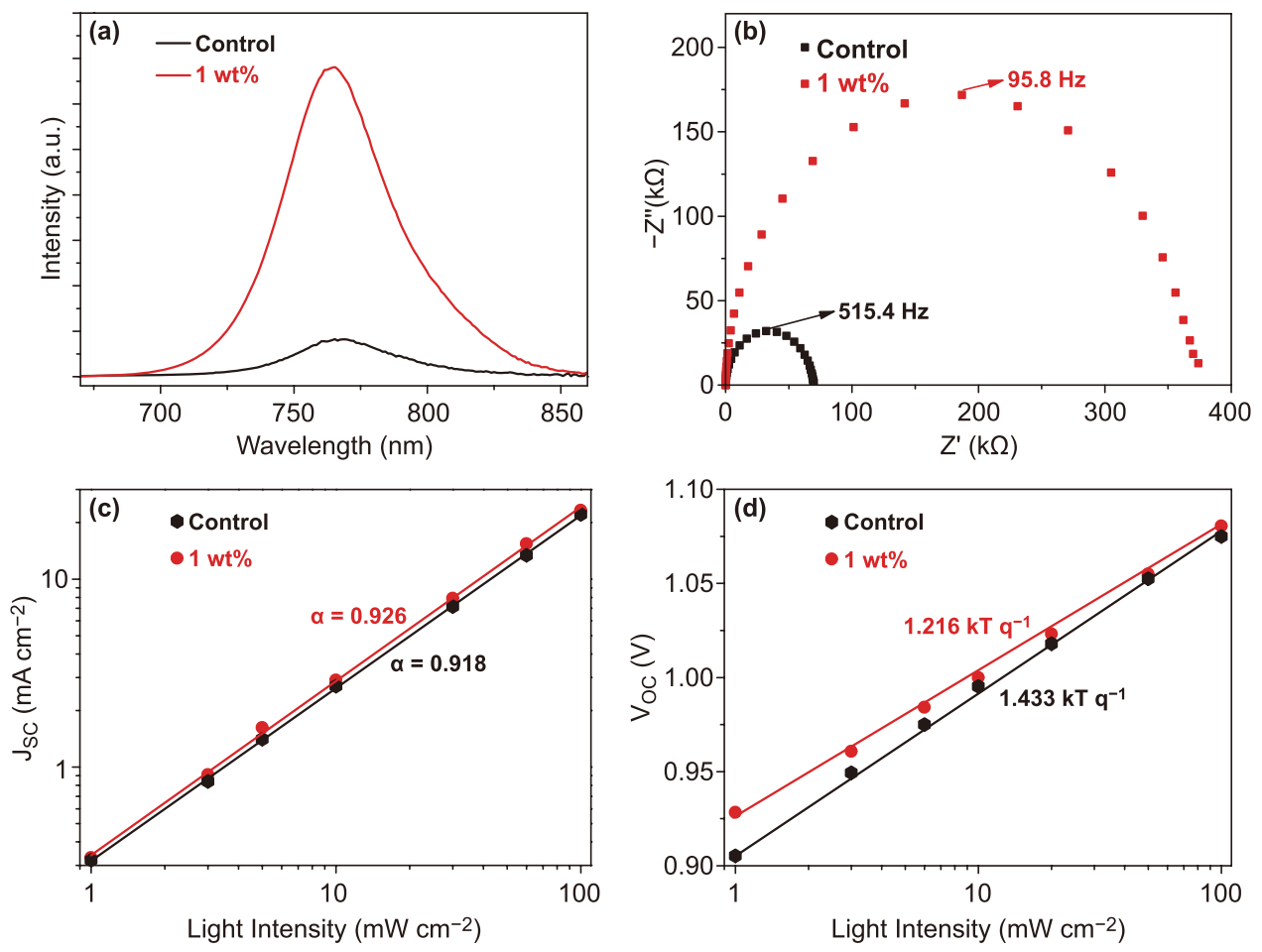

Fig. 5 a PL of the $\mathrm{MAPbI}_{3}$ films with and without PEA on glass substrates. b EIS spectra, c $J_{\mathrm{SC}}$ versus light intensity, and d $V_{\mathrm{OC}}$ versus light intensity of $\mathrm{MAPbI}_{3}$ devices with and without PEA 
the spectra are displayed in Fig. S7. The PL kinetics are fitted by the biexponential function below [Eq. (2)] [46]:

$Y=A_{1} \exp \left(-\frac{t}{\tau_{1}}\right)+A_{2} \exp \left(-\frac{t}{\tau_{2}}\right)+y_{0}$

where $\tau_{1}$ and $\tau_{2}$ are the lifetimes of the fast and slow recombination processes [47], and $A_{1}$ and $A_{2}$ represent the corresponding relative amplitudes. Detailed fitting parameters are summarized in Table S3. After PEA is added, $\tau_{1}$ and $\tau_{2}$ are prolonged from 4.2 and $42.5 \mathrm{~ns}$ to 6.0 and $69.3 \mathrm{~ns}$, respectively. Furthermore, the PL lifetimes were also measured when the two films are interfaced with PCBM and SpiroOMeTAD (Fig. S8). $\tau_{1}$ and $\tau_{2}$ are 2.8 and $6.8 \mathrm{~ns}$ for the PEA modified $\mathrm{MAPbI}_{3}$ film/PCBM, and are 3.9 and $9.4 \mathrm{~ns}$ for the $\mathrm{MAPbI}_{3}$ film/PCBM. The lifetimes are also shortened for the PEA modified $\mathrm{MAPbI}_{3}$ film/Spiro-OMeTAD, with $\tau_{1}$ and $\tau_{2}$ of 6.2 and $22.2 \mathrm{~ns}$, as compared to 5.3 and $33.1 \mathrm{~ns}$ for the $\mathrm{MAPbI}_{3}$ film/Spiro-OMeTAD (Table S4). These results indicate suppressed charge recombination and enhanced charge transfer in the $\mathrm{MAPbI}_{3}$ film with PEA [48]. Electrical impedance spectroscopy (EIS) was performed on the $\mathrm{MAPbI}_{3}$ devices with and without PEA under open-circuit conditions in a dark environment (Fig. 5b). It is apparent that the device with PEA has larger recombination resistance $R_{\text {rec, }}$ indicating that the film with PEA is in favor of suppressing carrier recombination $[49,50]$. In addition, the carrier lifetimes are also estimated from EIS from Eq. (3) [51-53]:

$\tau=\frac{1}{2 \pi f}$

where $f$ is the frequency of the highest point in EIS. The calculated $\tau$ is $0.31 \mathrm{~ms}$ for the control device, and $1.66 \mathrm{~ms}$ for the device with PEA. This longer carrier lifetime further demonstrates the PEA passivation benefit.

To estimate carrier trap state density in the $\mathrm{MAPbI}_{3}$ films with and without PEA, we performed space-charge-limited current (SCLC) measurements on hole-only and electrononly devices (Fig. S9, Supporting Information). The trap state densities are calculated from Eq. (4) [54]:

$N_{t}=\frac{2 V_{\mathrm{TFL}} \varepsilon_{0} \varepsilon_{r}}{q L^{2}}$

where $V_{\mathrm{TFL}}$ is the onset voltage of the trap-filled limit region in the dark $J-V$ curves, $\varepsilon_{0}$ and $\varepsilon_{r}$ represent the vacuum permittivity and the relative dielectric constant of $\mathrm{MAPbI}_{3}$, respectively, and $L$ is the thickness of the perovskite film. The result shows that the hole (electron) trap state density is decreased from $7.2 \times 10^{15}$ to $4.5 \times 10^{15} \mathrm{~cm}^{-3}\left(9.5 \times 10^{15}\right.$ to $5.5 \times 10^{15} \mathrm{~cm}^{-3}$ ).
We then explored the variation of $J_{\mathrm{SC}}$ and $V_{\mathrm{OC}}$ under different light intensities. The power law dependence of $J_{\mathrm{SC}}$ on the incident light intensity $P_{\text {light }}$ for the investigated devices is displayed in Fig. 5c, and the data are fitted by Eq. (5) [55-57]:

$J_{\mathrm{SC}} \propto P_{\text {light }}^{\alpha}$

Without recombination, $\alpha$ value is 1 . In practice, $\alpha$ will be lower than 1 because there always exists carrier recombination in a solar cell device [58-60]. The larger $\alpha$ is, the weaker the recombination is. The device with PEA has a larger $\alpha$ than the control device (0.926 vs 0.918 ), confirming that carrier recombination is suppressed in the device with PEA. We also investigated the dependence of $V_{\mathrm{OC}}$ on $P_{\text {light }}$ and found $V_{\mathrm{OC}}$ is logarithmically dependent on $P_{\text {light }}$ (Fig. 5d). The diode ideality factor $\mathrm{n}$ can be expressed by Eq. (6) $[50,61]$ :

$n \approx \frac{q}{k T} \frac{\mathrm{d} V_{\mathrm{OC}}}{\mathrm{d} \lg \left(P_{\text {light }}\right)}$

where $\mathrm{k}, \mathrm{q}, \mathrm{T}$ are Boltzmann constant, elementary charge and temperature, respectively. For an ideal device, $n$ equals 1. For a non-ideal device, $n$ is larger than 1 , and the larger $n$, the stronger the carrier recombination $[62,63]$. The control device possesses a large $n$ value of 1.433, suggesting severe carrier recombination inside the device. In contrast, the device with PEA exhibits a smaller $n$ value of 1.216 , indicating that carrier recombination is suppressed by PEA.

We then investigated the stability of the two devices in air stored in a dark environment. Figure $6 \mathrm{a}-\mathrm{d}$ displays $V_{\mathrm{OC}}, J_{\mathrm{SC}}$, $\mathrm{FF}$, and PCE variation in air (with $30 \pm 5 \%$ relative humidity). The $\mathrm{MAPbI}_{3}$ device with PEA remains at $95 \%$ of its original PCE after 30 days, while the control device only retains $60 \%$ of its original value. This significant improvement in stability could be primarily attributed to PEA filling the GB gaps, which plays a crucial role in blocking $\mathrm{H}_{2} \mathrm{O}$ and $\mathrm{O}_{2}$. Furthermore, PEA is hydrophobic and hence would naturally repel $\mathrm{H}_{2} \mathrm{O}$. The perovskite film became less hydrophilic when PEA is added (Fig. S10a, b). The $\mathrm{MAPbI}_{3}$ film with PEA shows a contact angle of $63.3^{\circ}$, while the control film shows a contact angle of $37.2^{\circ}$.

\subsection{Characterization of $\left(\mathrm{FAPbI}_{3}\right)_{1-\mathrm{x}}\left(\mathrm{MAPbBr}_{3}\right)_{\mathrm{x}}$ Devices with PEA}

Finally, we applied PEA to $\left(\mathrm{FAPbI}_{3}\right)_{1-\mathrm{x}}\left(\mathrm{MAPbBr}_{3}\right)_{\mathrm{x}}($ details are described in the Experimental Section). Figure $7 \mathrm{a}$ 

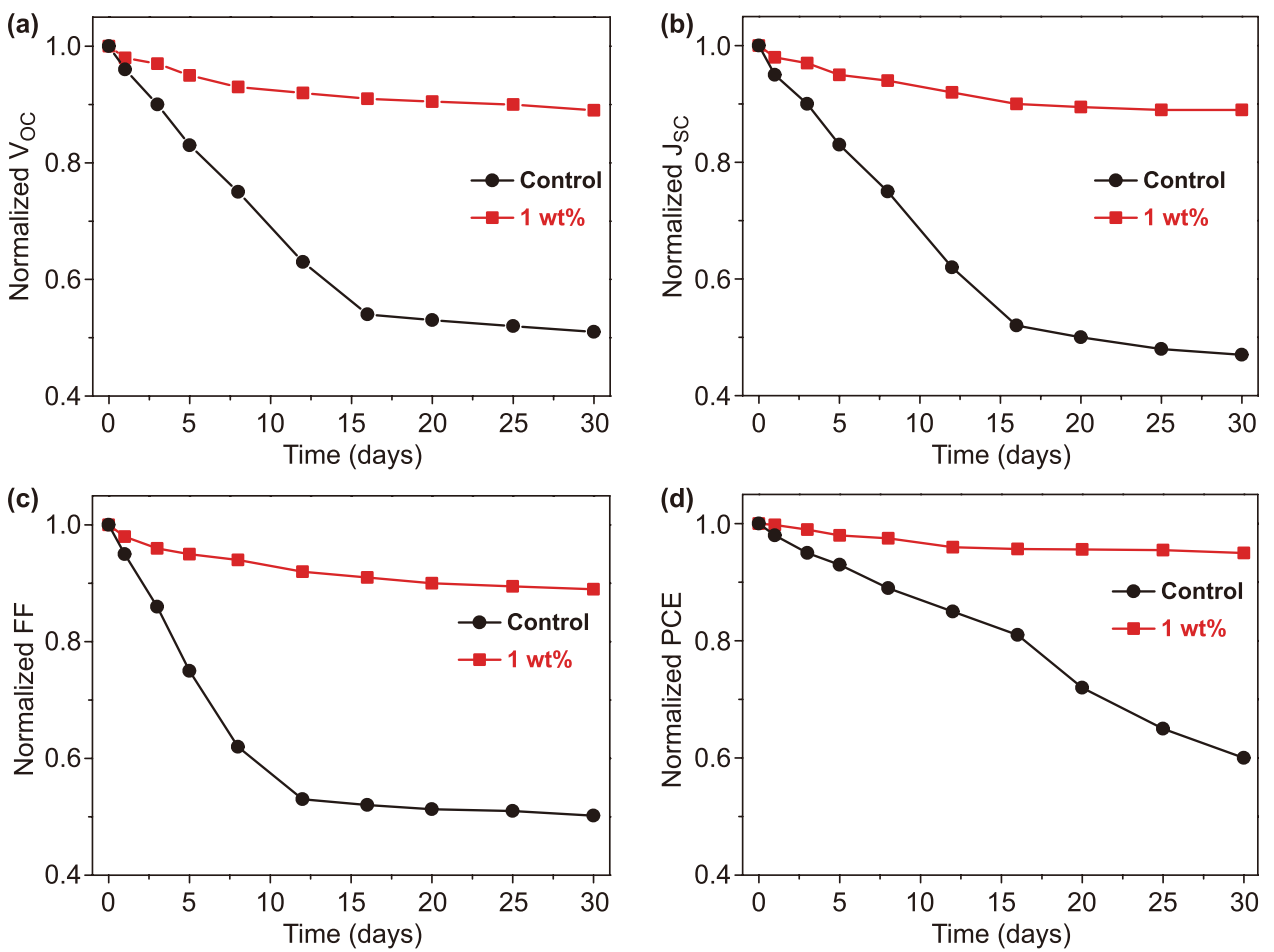

Fig. 6 Normalized a $V_{\mathrm{OC}}, \mathbf{b} J_{\mathrm{SC}}, \mathbf{c}$ FF, and $\mathbf{d} \mathrm{PCE}$ of the $\mathrm{MAPbI}_{3}$ devices with and without PEA vs time. The devices are stored in a dark environment under ambient air with $30 \pm 5 \%$ relative humidity
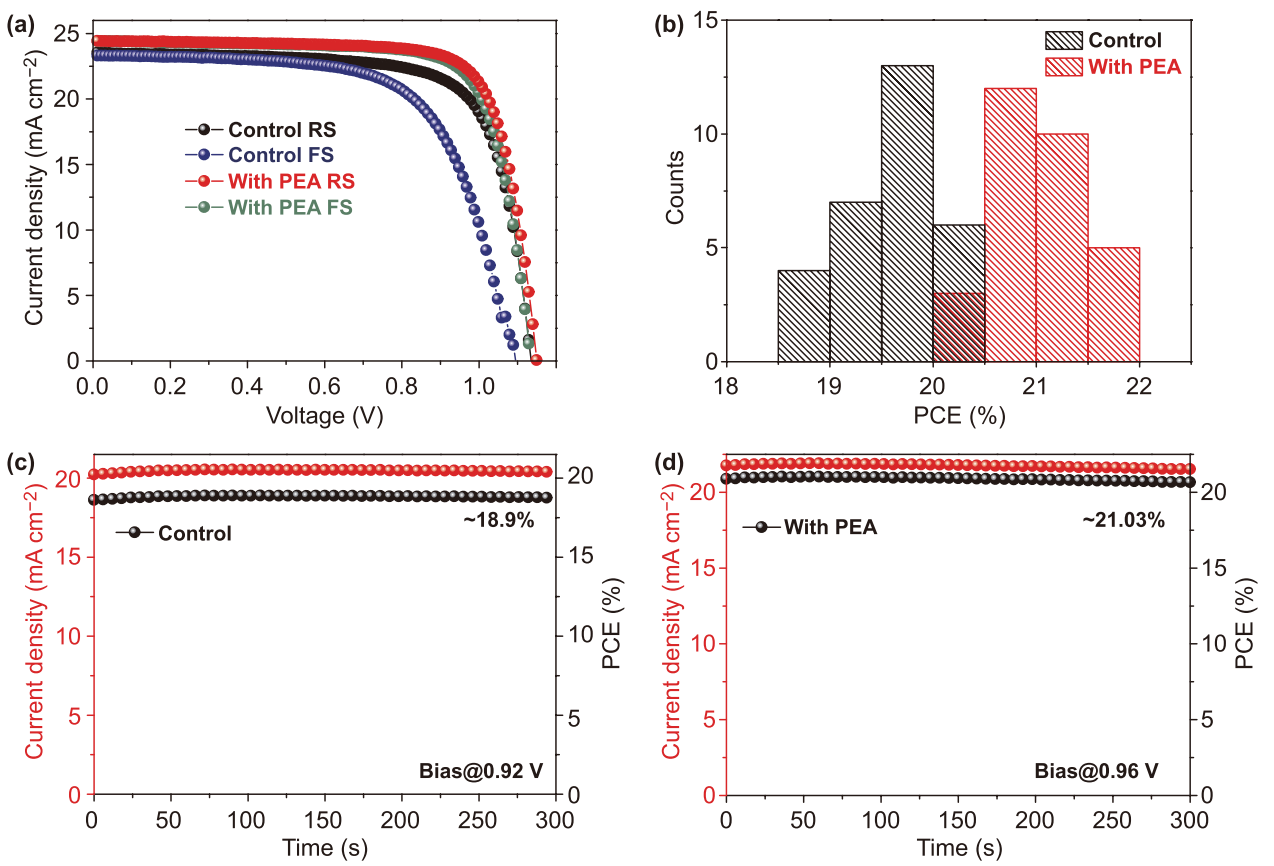

Fig. 7 a $J-V$ curves of the $\left(\mathrm{FAPbI}_{3}\right)_{1-\mathrm{x}}\left(\mathrm{MAPbBr}_{3}\right)_{\mathrm{x}}$ PSCs with and without PEA. b Histogram of PCE distribution. c Steady-state current density and efficiency at maximum power point of the device without, and $\mathbf{d}$ with PEA 
demonstrates $J-V$ characteristics of the corresponding devices with and without PEA. The device parameters are displayed in Table S5. The control device exhibits a PCE of $19.66 \%$, with $V_{\mathrm{OC}}$ of $1.13 \mathrm{~V}, J_{\mathrm{SC}}$ of $23.51 \mathrm{~mA} \mathrm{~cm}^{-2}$, and FF $73.7 \%$, while the device with PEA delivers a significantly improved PCE of $21.60 \%$, with $V_{\mathrm{OC}}$ of $1.15 \mathrm{~V}, J_{\mathrm{SC}}$ of $24.42 \mathrm{~mA} \mathrm{~cm}^{-2}$, and $\mathrm{FF}$ of $76.9 \%$. In addition, the control device shows a very high $\mathrm{HI}$ of 0.15 , while the device with PEA is significantly lower, at 0.02 . Their PCEs distributions are provided in Fig. $7 \mathrm{~b}$. Figure $7 \mathrm{c}$, d shows the steady-state efficiency at maximum power point for the control device and the device with PEA, respectively. It is observed the PCE of the device with PEA stabilizes at $21.02 \%$, while that of the control device remains at $18.90 \%$.

\section{Conclusion}

We employed PEA for perovskite surface and GB passivation. The ether-oxygen unshared electron pair in PEA activates to form a crosslinking complex with lead ions, resulting in the decrease in trap state density and inhibition of non-radiative recombination in the perovskite films. The $\mathrm{MAPbI}_{3}$-based cells with PEA obtain an improved PCE from 17.18 to $18.87 \%$, with significantly reduced hysteresis from 9.1 to $1.1 \%$. Moreover, the device maintains $95 \%$ of its original PCE after 30 days without any encapsulation. In contrast, the control device retains only $60 \%$ of its initial PCE under the same condition. For $\left(\mathrm{FAPbI}_{3}\right)_{1-\mathrm{x}}\left(\mathrm{MAPbBr}_{3}\right)_{\mathrm{x}}$-based cells, the hysteresis is significantly suppressed from 15.0 to $2.0 \%$, and the PCE is enhanced from 19.66 to $21.60 \%$. This work demonstrates that PEA is a very efficient trap passivator for stable high-efficiency PSCs.

\section{Experimental Section}

\subsection{Materials}

$\mathrm{PbI}_{2}$, MAI, FAI, MABr, MABr, Spiro-OMeTAD, and LiTFSI are purchased from Xi' an Baolaite Technology Crop. $\mathrm{TiCl}_{4}, \mathrm{SnO}_{2}$ colloid precursor ( $15 \%$ in $\mathrm{H}_{2} \mathrm{O}$ colloidal dispersion), PEA, DMF, DMSO and chlorobenzene are purchased from Alfa Aesar. 4-tert-butylpyridine (TBP, 96\% purity), PCBM, PEDOT: PSS are obtained from Sigma-Aldrich. All of the above materials and chemicals are used as received.

\subsection{Solution Preparation}

The $\mathrm{MAPbI}_{3}$ precursor solution (199 mg MAI and $461 \mathrm{mg}$ $\mathrm{PbI}_{2}$ dissolved in $800 \mu \mathrm{L}$ DMF and $200 \mu \mathrm{L}$ DMSO mixed solvent) is prepared in a $\mathrm{N}_{2}$ glove box. The PEA additive (concentration varying from $0 \mathrm{wt} \%$ to $3 \mathrm{wt} \%$ ) is added in the $\mathrm{MAPbI}_{3}$ precursor solution and is further stirred for $2 \mathrm{~h}$ at $60{ }^{\circ} \mathrm{C}$ on a hotplate. The solution is filtered before use. The $\left(\mathrm{FAPbI}_{3}\right)_{1-\mathrm{x}}\left(\mathrm{MAPbBr}_{3}\right)_{\mathrm{x}}$ film is prepared by a two-step spin-coating process. $\mathrm{PbI}_{2}$ solution $(760 \mathrm{mg}$ $\mathrm{PbI}_{2}$ in $1000 \mu \mathrm{L}$ DMF and $160 \mu \mathrm{L}$ DMSO) is added by $0.1 \mathrm{wt} \%$ PEA additive and is stirred for $2 \mathrm{~h}$ at $60^{\circ} \mathrm{C}$. The mixed organic salt solution for the second step is $73.3 \mathrm{mg}$ $\mathrm{FAI} / 7.7 \mathrm{mg} \mathrm{MACl} / 7.3 \mathrm{mg} \mathrm{MABr}$ in $1 \mathrm{~mL}$ IPA solvent. The Spiro-OMeTAD solution is obtained by dissolving $72.3 \mathrm{mg}$ Spiro-OMeTAD, $35 \mu \mathrm{L}$ LI-TSFI solution (260 $\mathrm{mg} \mathrm{mL}^{-1}$ in acetonitrile), and $28.8 \mu \mathrm{L} \mathrm{TBP}$ in $1 \mathrm{~mL}$ of chlorobenzene.

\subsection{Fabrication of PSCs}

$\mathrm{MAPbI}_{3}$ devices FTO-coated glass is sequentially ultrasonically cleaned in deionized water, acetone, and isopropanol. The substrate is then dried by $\mathrm{N}_{2}$ flow and treated by ozone plasma for $15 \mathrm{~min}$. Prior to depositing the perovskite layer, the $\mathrm{TiO}_{2}$ electron transport layer is fabricated by immersing the substrate in hot $\left(70{ }^{\circ} \mathrm{C}\right) \mathrm{TiCl}_{4}$ aqueous solution (with a concentration of $200 \mathrm{mM}$ ) for $1 \mathrm{~h}$, and is further heated at $100{ }^{\circ} \mathrm{C}$ for $1 \mathrm{~h}$. The $\mathrm{MAPbI}_{3}$ precursor is spin-coated by a successive procedure of $1000 \mathrm{rpm}$ for $10 \mathrm{~s}$ and $4000 \mathrm{rpm}$ for $30 \mathrm{~s}$ on top of the $\mathrm{TiO}_{2}$ film. In the second step, $20 \mathrm{~s}$ before the ending of the procedure, $100 \mu \mathrm{L}$ chlorobenzene is rapidly dropped onto the surface of the sample. Afterwards, the sample is annealed at $100{ }^{\circ} \mathrm{C}$ for $10 \mathrm{~min}$ and subsequently, the Spiro-OMeTAD solution is spin-coated on the perovskite film at $4000 \mathrm{rpm}$ for $30 \mathrm{~s}$. The sample is then preserved in a dry dark box for $20 \mathrm{~h}$. The device is completed by thermally deposition a 70-nm Au electrode.

$\left(\mathrm{FAPbI}_{3}\right)_{1-\mathrm{x}}\left(\mathbf{M A P b B r}_{3}\right)_{\mathrm{x}}$ devices ITO-coated glass is sequentially ultrasonically cleaned in deionized water, acetone, isopropanol, dried by $\mathrm{N}_{2}$ flow, and then treated by ozone plasma for $15 \mathrm{~min}$. The $\mathrm{SnO}_{2}$ electron transport layer is deposited on the ITO substrate by spin-coating 
the $\mathrm{SnO}_{2}$ precursor (2\%, diluted by water) at $3000 \mathrm{rpm}$ for $30 \mathrm{~s}$, and then heated at $150{ }^{\circ} \mathrm{C}$ for $30 \mathrm{~min}$. The $\left(\mathrm{FAPbI}_{3}\right)_{1-\mathrm{x}}\left(\mathrm{MAPbBr}_{3}\right)_{\mathrm{x}}$ film is fabricated by spin-coating the $\mathrm{PbI}_{2}$ solution at $1600 \mathrm{rpm}$ for $10 \mathrm{~s}$ and then $4000 \mathrm{rpm}$ for $30 \mathrm{~s}$. The film is annealed at $70{ }^{\circ} \mathrm{C}$ for $2 \mathrm{~min}$, followed by spin-coating the mixed solution (FAI/MACl/MABr) at $2000 \mathrm{rpm}$ for $23 \mathrm{~s}$ and an annealing process at $140{ }^{\circ} \mathrm{C}$ for $20 \mathrm{~min}$ in air. The following steps for Spiro-OMeTAD film and $\mathrm{Au}$ electrode replicate those for the $\mathrm{MAPbI}_{3}$ devices.

Hole-only devices The PEDOT: PSS is prepared by spin-coating the solution at $2000 \mathrm{rpm}$ for $50 \mathrm{~s}$ on the ITO substrates, and is heated at $140{ }^{\circ} \mathrm{C}$ for $10 \mathrm{~min}$. The perovskite film is then deposited using the previous method. The Spiro-OMeTAD layer is then fabricated by spin-coating at 2000 rpm for 50 s. Finally, a 70-nm Au electrode underwent thermal deposition.

Electron-only devices $\mathrm{The}^{\mathrm{SnO}_{2}}$ layer and the perovskite layer are sequentially deposited on the ITO substrates using the previous method. The PCBM layer is then made from a precursor solution $\left(15 \mathrm{mg} \mathrm{mL}^{-1}\right.$ in chlorobenzene) via spincoating at $2000 \mathrm{rpm}$ for $50 \mathrm{~s}$. Finally, a $100 \mathrm{~nm} \mathrm{Ag}$ electrode underwent thermal deposition.

\subsection{Characterization}

TOF-SIMS tests in the positive ion mode were conducted on a ToF-SIMS V instrument (ION-TOF GmbH, Münster, Germany). A pulsed $30 \mathrm{keV} \mathrm{Bi}_{3}{ }^{+}$primary ion beam was used for the analysis with the beam current of $0.98 \mathrm{pA}$ at a pulse repeating frequency of $10 \mathrm{kHz}$. The sputtering beam was $10 \mathrm{keV} \mathrm{Ar}{ }_{1700}{ }^{+}$with the beam current adjusted to $2 \mathrm{nA}$. The analysis area was $100 \times 100 \mu^{2}$ at the center of a crater of $250 \times 250 \mu^{2}$. During the measurements, a low-energy flood gun was used for charge compensation. FTIR spectra were tested by TENSOR-27 (Bruker, Germany), and the XPS result was obtained by ESCALAB250XI (VG, America). SEM images were obtained by S-4800(Hitachi, Japan). $\mathrm{XRD}$ is performed on $\mathrm{D} / \max 2500$ (Rigaku, Japan) with a Cu Ka radiation source $(\lambda=1.5418 \AA$ ). UV-Vis absorption spectra were characterized by UV-2600 (SHIMADZ, Japan). $J-V$ curves were obtained by a Keithley 2400 system, with a light intensity of $100 \mathrm{~mW} \mathrm{~cm}^{-2}$ under an AM 1.5 solar simulator. IPCE spectra were recorded by a computercontrolled system. PL and TRPL spectra were recorded by a spectrofluorometer (FLS980, Edinburgh, England). EIS was performed on an IM6ex Electrochemical Workstation (Zahener, Germany), and the frequency range used is $1 \mathrm{MHz}$ to $1 \mathrm{~Hz}$.

Acknowledgements Financial support for this research is provided by the National Key Research Program of China (2016YFA0200104) and the Strategic Priority Research Program of the Chinese Academy of Sciences (XDB12030200).

Open Access This article is licensed under a Creative Commons Attribution 4.0 International License, which permits use, sharing, adaptation, distribution and reproduction in any medium or format, as long as you give appropriate credit to the original author(s) and the source, provide a link to the Creative Commons licence, and indicate if changes were made. The images or other third party material in this article are included in the article's Creative Commons licence, unless indicated otherwise in a credit line to the material. If material is not included in the article's Creative Commons licence and your intended use is not permitted by statutory regulation or exceeds the permitted use, you will need to obtain permission directly from the copyright holder. To view a copy of this licence, visit http://creativecommons.org/licenses/by/4.0/.

Electronic supplementary material The online version of this article (https://doi.org/10.1007/s40820-020-00517-y) contains supplementary material, which is available to authorized users.

\section{References}

1. M.M. Lee, J. Teuscher, T. Miyasaka, T.N. Murakami, H.J. Snaith, Efficient hybrid solar cells based on meso-superstructured organometal halide perovskites. Science 338(6107), 643-647 (2012). https://doi.org/10.1126/science.1228604

2. S.D. Stranks, G.E. Eperon, G. Grancini, C. Menelaou, M.J.P. Alcocer et al., Electron-hole diffusion lengths exceeding 1 micrometer in an organometal trihalide perovskite absorber. Science 342(6156), 341-344 (2013). https://doi.org/10.1126/science.1243982

3. C. Wehrenfennig, G.E. Eperon, M.B. Johnston, H.J. Snaith, L.M. Herz, High charge carrier mobilities and lifetimes in organolead trihalide perovskites. Adv. Mater. 26(10), 15841589 (2014). https://doi.org/10.1002/adma.201305172

4. H. Zhou, Q. Chen, G. Li, S. Luo, T.B. Song et al., Interface engineering of highly efficient perovskite solar cells. Science 345(6196), 542-546 (2014). https://doi.org/10.1126/scien ce. 1254050

5. N.J. Jeon, J.H. Noh, W.S. Yang, Y.C. Kim, S. Ryu, J. Seo, S.I. Seok, Compositional engineering of perovskite materials for high-performance solar cells. Nature 517, 476-480 (2015). https://doi.org/10.1038/nature14133

6. A. Kojima, K. Teshima, Y. Shirai, T. Miyasaka, Organometal halide perovskites as visible-light sensitizers for photovoltaic cells. J. Am. Chem. Soc. 131(17), 6050-6051 (2009). https:// doi.org/10.1021/ja809598r 
7. National renewable energy laboratory, Best research-cell efficiencies. www.nrel.gov/pv/assets/pdfs/best-research-cell-efcie ncies.20190802.pdf

8. T. Matsui, H. Jia, M. Kondo, Thin film solar cells incorporating microcrystalline $\mathrm{Si}_{1-\mathrm{x}} \mathrm{Ge}_{\mathrm{x}}$ as efficient infrared absorber: an application to double junction tandem solar cells. Prog. Photovoltaics Res. Appl. 18(1), 48-53 (2010). https://doi. org/10.1002/pip.922

9. W. Ke, C. Xiao, C. Wang, B. Saparov, H.S. Duan et al., Employing lead thiocyanate additive to reduce the hysteresis and boost the fill Factor of planar perovskite solar cells. Adv. Mater. 28(26), 5214-5221 (2016). https://doi.org/10.1002/ adma.201600594

10. Y. Zhang, L. Tan, Q. Fu, L. Chen, T. Ji, X. Hu, Y. Chen, Enhancing the grain size of organic halide perovskites by sulfonate-carbon nanotube incorporation in high performance perovskite solar cells. Chem. Commun 52, 5674 (2016). https://doi.org/10.1039/c6cc00268d

11. Q. Chen, H. Zhou, T. Bin Song, S. Luo, Z. Hong et al., Controllable self-induced passivation of hybrid lead iodide perovskites toward high performance solar cells. Nano Lett. 14(7), 4158-4163 (2014). https://doi.org/10.1021/nl501838y

12. M. Saliba, T. Matsui, K. Domanski, J.Y. Seo, A. Ummadisingu et al., Incorporation of rubidium cations into perovskite solar cells improves photovoltaic performance. Science 354(6309), 206-209 (2016). https://doi.org/10.1126/scien ce.aah5557

13. M. Kot, C. Das, Z. Wang, K. Henkel, Z. Rouissi et al., Roomtemperature atomic layer deposition of $\mathrm{Al}_{2} \mathrm{O}_{3}$ : impact on efficiency, stability and surface properties in perovskite solar cells. Chemsuschem 9(24), 3401-3406 (2016). https://doi. org/10.1002/cssc. 201601186

14. L. Chu, W. Ahmad, W. Liu, J. Yang, R. Zhang et al., Lead-free halide double perovskite materials: a new superstar towards green and stable optoelectronic applications. Nano-Micro Lett. 11, 16 (2019). https://doi.org/10.1007/s40820-019-0244-6

15. F. Wang, W. Geng, Y. Zhou, H.-H. Fang, C.-J. Tong et al., Perovskites enabling high-efficiency and air-stable photovoltaic cells. Adv. Mater. 28, 9986-9992 (2016). https://doi. org/10.1002/adma.201603062

16. F. Wang, A. Shimazaki, F. Yang, K. Kanahashi, K. Matsuki et al., Highly efficient and stable perovskite solar cells by interfacial engineering using solution-processed polymer layer. J. Phys. Chem. C 121, 1562-1568 (2017). https://doi. org/10.1021/acs.jpcc.6b12137

17. W. Liu, N. Liu, S. Ji, H. Hua, Y. Ma et al., Perfection of perovskite grain boundary passivation by rhodium incorporation for efficient and stable solar cells. Nano-Micro Lett. 12, 119 (2020). https://doi.org/10.1007/s40820-020-00457-7

18. M.E. Kayesh, T.H. Chowdhury, K. Matsuishi, R. Kaneko, S. Kazaoui et al., Enhanced photovoltaic performance of $\mathrm{FASnI}_{3}$-based perovskite solar cells with hydrazinium chloride coadditive. ACS Energy Lett. 3(7), 1584-1589 (2018). https://doi.org/10.1021/acsenergylett.8b00645

19. L. Liu, S. Huang, Y. Lu, P. Liu, Y. Zhao et al., Grain-boundary "patches" by in situ conversion to enhance perovskite solar cells stability. Adv. Mater. 30(29), 1800544 (2018). https:// doi.org/10.1002/adma.201800544

20. J. Jiang, Q. Wang, Z. Jin, X. Zhang, J. Lei et al., Polymer doping for high-efficiency perovskite solar cells with improved moisture stability. Adv. Energy Mater. 8(3), 1701757 (2018). https://doi.org/10.1002/aenm.201701757

21. L. Meng, C. Sun, R. Wang, W. Huang, Z. Zhao et al., Tailored phase conversion under conjugated polymer enables thermally stable perovskite solar cells with efficiency exceeding $21 \%$. J. Am. Chem. Soc. 140(49), 17255-17262 (2018). https://doi. org/10.1021/jacs.8b10520

22. J. Wei, H. Li, Y. Zhao, W. Zhou, R. Fu et al., Suppressed hysteresis and improved stability in perovskite solar cells with conductive organic network. Nano Energy 26, 139-147 (2016). https://doi.org/10.1016/j.nanoen.2016.05.023

23. L. Zuo, H. Guo, D.W. deQuilettes, S. Jariwala, N. De Marco et al., Polymer-modified halide perovskite films for efficient and stable planar heterojunction solar cells. Sci. Adv. 3, e1700106 (2017). https://doi.org/10.1126/sciadv.1700106

24. P.-L. Qin, G. Yang, Z.-W. Ren, S.H. Cheung, S.K. So et al., Stable and efficient organo-metal halide hybrid perovskite solar cells via $\pi$-conjugated Lewis base polymer induced trap passivation and charge extraction. Adv. Mater. 30(12), 1706126 (2018). https://doi.org/10.1002/adma.201706126

25. A. Ng, Z. Ren, Q. Shen, S.H. Cheung, H.C. Gokkaya et al., Crystal engineering for low defect density and high efficiency hybrid chemical vapor deposition grown perovskite solar cells. ACS Appl. Mater. Interfaces 8(48), 32805-32814 (2016). https://doi.org/10.1021/acsami.6b07513

26. W.-J. Yin, H. Chen, T. Shi, S.-H. Wei, Y. Yan, Origin of high electronic quality in structurally disordered $\mathrm{CH}_{3} \mathrm{NH}_{3} \mathrm{PbI}_{3}$ and the passivation effect of $\mathrm{Cl}$ and $\mathrm{O}$ at grain boundaries. Adv. Electron. Mater. 1(6), 1500044 (2015). https://doi. org/10.1002/aelm.201500044

27. P. Qin, T. Wu, Z. Wang, X. Zheng, X. Yu, G. Fang, G. Li, Vitrification transformation of poly(ethylene oxide) activating interface passivation for high-efficiency perovskite solar cells. Sol. RRL 3, 1900134 (2019). https://doi.org/10.1002/ solr.201900134

28. M. Kim, S.G. Motti, R. Sorrentino, A. Petrozza, Enhanced solar cell stability by hygroscopic polymer passivation of metal halide perovskite thin film. Energy Environ. Sci. 11, 2609-2619 (2018). https://doi.org/10.1039/C8EE01101J

29. P. Guo, Q. Ye, X. Yang, J. Zhang, F. Xu et al., Surface \& grain boundary co-passivation by fluorocarbon based bifunctional molecules for perovskite solar cells with efficiency over 21\%. J. Mater. Chem. A 7, 2497-2506 (2019). https:// doi.org/10.1039/c8ta11524a

30. P. Qin, Q. He, G. Yang, X. Yu, L. Xiong, G. Fang, Metal ions diffusion at heterojunction chromium Oxide/ $/ \mathrm{CH}_{3} \mathrm{NH}_{3} \mathrm{PbI}_{3}$ interface on the stability of perovskite solar cells. Surf. Interfaces 10, 93-99 (2018). https://doi.org/10.1016/j.surfi n.2017.12.006

31. R. Morent, N. De Geyter, C. Leys, L. Gengembreb, Comparison between XPS- and FTIR- analysis of plasma-treated 
polypropylene film surfaces. E. Payenb. Surf. Interface Anal. 40, 597-600 (2008). https://doi.org/10.1002/sia.2619

32. W. Zhou, D. Li, Z. Xiao, Z. Wen, M. Zhang et al., Zwitterion coordination induced highly orientational order of $\mathrm{CH}_{3} \mathrm{NH}_{3} \mathrm{PbI}_{3}$ perovskite film delivers a high open circuit voltage exceeding 1.2 V. Adv. Funct. Mater. 29(23), 1901026 (2019). https://doi.org/10.1002/adfm.201901026

33. S. Yang, S. Chen, E. Mosconi, Y. Fang, X. Xiao et al., Stabilizing halide perovskite surfaces for solar cell operation with wide-bandgap lead oxysalts. Science 365(6452), 473-478 (2019). https://doi.org/10.1126/science.aax3294

34. J.-W. Lee, D.-H. Kim, H.-S. Kim, S.-W. Seo, S.M. Cho, N.-G. Park, Formamidinium and cesium hybridization for photo- and moisture- stable perovskite solar cell. Adv. Energy Mater. 5(20), 1501310 (2015). https://doi. org/10.1002/aenm.201501310

35. B. Li, J. Zhen, Y. Wan, X. Lei, Q. Liu et al., Anchoring fullerene onto perovskite film via grafting pyridine toward enhanced electron transport in high-efficiency solar cells. ACS Appl. Mater. Interfaces 10(38), 32471-32482 (2018). https://doi.org/10.1021/acsami.8b11459

36. R. Lindblad, D. Bi, B.W. Park, J. Oscarsson, M. Gorgoi et al., Electronic structure of $\mathrm{TiO}_{2} / \mathrm{CH}_{3} \mathrm{NH}_{3} \mathrm{PbI}_{3}$ perovskite solar cell interfaces. J. Phys. Chem. Lett. 5(4), 648-653 (2014). https://doi.org/10.1021/jz402749f

37. D. Bi, C. Yi, J. Luo, J.D. Décoppet, F. Zhang et al., Polymertemplated nucleation and crystal growth of perovskite films for solar cells with efficiency greater than $21 \%$. Nat. Energy 1, 16142 (2016). https://doi.org/10.1038/nenergy.2016.142

38. Y. Wu, X. Yang, W. Chen, Y. Yue, M. Cai et al., Perovskite solar cells with $18.21 \%$ efficiency and area over $1 \mathrm{~cm}^{2}$ fabricated by heterojunction engineering. Nat. Energy 1, 16148 (2016). https://doi.org/10.1038/nenergy.2016.148

39. T. Niu, J. Liu, R. Munir, J. Li, D. Barrit et al., Stable highperformance perovskite solar cells via grain boundary passivation. Adv. Mater. 30(16), 1706576 (2018). https://doi. org/10.1002/adma.201706576

40. W. Chen, Y. Wang, G. Pang, C.W. Koh, A.B. Djurišxić et al., Conjugated polymer-assisted grain boundary passivation for efficient inverted planar perovskite solar cells. Adv. Funct. Mater. 29(27), 1808855 (2019). https://doi.org/10.1002/ adfm. 201808855

41. C. Sun, Y. Guo, B. Fang, J. Yang, B. Qin et al., Enhanced photovoltaic performance of perovskite solar cells using polymer P(VDF-TrFE) as a processed additive. J. Phys. Chem. C 120(24), 12980-12988 (2016). https://doi.org/10.1021/ acs.jpcc.6b05255

42. H. Cho, S.H. Jeong, M.H. Park, Y.H. Kim, C. Wolf et al., Overcoming the electroluminescence efficiency limitations of perovskite light-emitting diodes. Science 350(6265), 1222-1225 (2015). https://doi.org/10.1126/science.aad1818

43. X. Dong, X. Fang, M. Lv, B. Lin, S. Zhang, J. Ding, N. Yuan, Improvement of the humidity stability of organicinorganic perovskite solar cells using ultrathin $\mathrm{Al}_{2} \mathrm{O}_{3}$ layers prepared by atomic layer deposition. J. Mater. Chem. A 3, 5360-5367 (2015). https://doi.org/10.1039/c4ta06128d
44. Y. Yuan, J. Huang, Ion migration in organometal trihalide perovskite and its impact on photovoltaic efficiency and stability. Acc. Chem. Res. 49(2), 286-293 (2016). https://doi. org/10.1021/acs.accounts.5b00420

45. X. Yi, Z. Zhang, A. Chang, Y. Mao, Y. Luan et al., Incorporating $\mathrm{CsF}$ into the $\mathrm{PbI}_{2}$ film for stable mixed cation-halide perovskite solar cells. Adv. Energy Mater. 9, 1901726 (2019). https://doi.org/10.1002/aenm.201901726

46. J. Yang, C. Liu, C. Cai, X. Hu, Z. Huang et al., High-performance perovskite solar cells with excellent humidity and thermo-stability via fluorinated perylenediimide. Adv. Energy Mater. 9, 190019810 (2019). https://doi.org/10.1002/ aenm.201900198

47. R. Wang, J. Xue, L. Meng, J.-W. Lee, Z. Zhao et al., Caffeine improves the performance and thermal stability of perovskite solar cells. Joule 3, 1464-1477 (2019). https://doi. org/10.1016/j.joule.2019.04.005

48. L. Zhou, Z. Lin, Z. Ning, T. Li, X. Guo et al., Highly efficient and stable planar perovskite solar cells with modulated diffusion passivation toward high power conversion efficiency and ultrahigh fill factor. Sol. RRL 3, 1900293 (2019). https://doi. org/10.1002/solr.201900293

49. A. Guerrero, G. Garcia-Belmonte, I. Mora-Sero, J. Bisquert, Y.S. Kang et al., Properties of contact and bulk impedances in hybrid lead halide perovskite solar cells including inductive loop elements. J. Phys. Chem. C 120(15), 8023-8032 (2016). https://doi.org/10.1021/acs.jpcc.6b01728

50. S.R. Cowan, A. Roy, A.J. Heeger, Recombination in polymer-fullerene bulk heterojunction solar cells. Phys. Rev. B 82, 245207 (2010). https://doi.org/10.1103/PhysRevB.82.245207

51. J. Chen, Z. Wan, J. Liu, S.Q. Fu, F. Zhang et al., Growth of compact $\mathrm{CH}_{3} \mathrm{NH}_{3} \mathrm{PbI}_{3}$ thin films governed by the crystallization in $\mathrm{PbI}_{2}$ matrix for efficient planar perovskite solar cells. ACS Appl. Mater. Interfaces 10(10), 8649-8658 (2018). https ://doi.org/10.1021/acsami.7b18667

52. Q. Dong, Y. Fang, Y. Shao, P. Mulligan, J. Qiu, L. Cao, J. Huang, Electron-hole diffusion lengths $>175 \mu \mathrm{m}$ in solutiongrown $\mathrm{CH}_{3} \mathrm{NH}_{3} \mathrm{PbI}_{3}$ single crystals. Science 347(6225), 967970 (2015). https://doi.org/10.1126/science.aaa5760

53. S.M. Ali, S.M. Ramay, M.H. Aziz, N. ur-Rehman, M.S. AlGarawi et al., Efficiency enhancement of perovskite solar cells by incorporation of CdS quantum dot through fast electron injection. Org. Electron. 62, 21-25 (2018). https://doi. org/10.1016/j.orgel.2018.07.012

54. P. Li, Y. Zhang, C. Liang, G. Xing, X. Liu et al., Phase pure 2D perovskite for high-performance $2 \mathrm{D}-3 \mathrm{D}$ heterostructured perovskite solar cells. Adv. Mater. 30, 1805323 (2018). https ://doi.org/10.1002/adma.201805323

55. A.K.K. Kyaw, D.H. Wang, D. Wynands, J. Zhang, T.Q. Nguyen, G.C. Bazan, A.J. Heeger, Improved light harvesting and improved efficiency by insertion of an optical spacer $(\mathrm{ZnO})$ in solution-processed small-molecule solar cells. Nano Lett. 13(8), 3796-3801 (2013). https://doi.org/10.1021/nl401 $758 \mathrm{~g}$ 
56. H. Li, J. Cao, Q. Zhou, L. Ding, J. Wang, High-performance inverted PThTPTI: PC71BM solar cells. Nano Energy 15, 125 (2015). https://doi.org/10.1016/j.nanoen.2015.04.016s

57. D. Bi, L. Yang, G. Boschloo, A. Hagfeldt, E.M.J. Johansson, Effect of different hole transport materials on recombination in $\mathrm{CH}_{3} \mathrm{NH}_{3} \mathrm{PbI}_{3}$ perovskite-sensitized mesoscopic solar cells. J. Phys. Chem. Lett. 4(9), 1532-1536 (2013). https://doi. org/10.1021/jz400638x

58. L.J.A. Koster, V.D. Mihailetchi, H. Xie, P.W.M. Blom, Origin of the light intensity dependence of the short-circuit current of polymer/fullerene solar cells. Appl. Phys. Lett. 87, 203502 (2005). https://doi.org/10.1063/1.2130396

59. V.D. Mihailetchi, J. Wildeman, P.W.M. Blom, Space-charge limited photocurrent. Phys. Rev. Lett. 94, 126602 (2005). https ://doi.org/10.1103/PhysRevLett.94.126602

60. H. Li, Z.G. Zhang, Y. Li, J. Wang, Tunable open-circuit voltage in ternary organic solar cells. Appl. Phys. Lett. 101, 163302 (2012). https://doi.org/10.1063/1.4761246
61. B. Qi, J. Wang, Open-circuit voltage in organic solar cells. J. Mater. Chem. 22, 24315-24325 (2012). https://doi. org/10.1039/C2JM33719C

62. M.M. Mandoc, F.B. Kooistra, J.C. Hummelen, B. De Boer, P.W.M. Blom, Effect of traps on the performance of bulk heterojunction organic solar cells. Appl. Phys. Lett. 91, 263505 (2007). https://doi.org/10.1063/1.2821368

63. S.R. Cowan, W.L. Leong, N. Banerji, G. Dennler, A.J. Heeger, Identifying a threshold impurity level for organic solar cells: enhanced first-order recombination via well-defined $\mathrm{PC}_{84} \mathrm{BM}$ traps in organic bulk Heterojunction solar cells. Adv. Funct. Mater. 21(16), 3083-3092 (2011). https://doi.org/10.1039/ C2JM33719C 